\title{
Long-Term Response to GH Therapy in Short Children With a Delayed Infancy-Childhood Transition (DICT)
}

\author{
KERSTIN ALBERTSSON-WIKLAND, BERIT KRISTRÖM, BJÖRN JONSSON, AND ZE’EV HOCHBERG
}

\begin{abstract}
Göteborg Pediatric Growth Research Center (GP-GRC), [K.A.-W., B.K.], The Sahlgrenska Academy at University of Gothenburg, SE-41685 Gothenburg, Sweden; Department of Clinical Science [B.K.], Umeå University, SE-90185 Umeå, Sweden; Department of Women and Child Health [B.J.], Uppsala University, SE-75185 Uppsala, Sweden; Department of Pediatric Endocrinology [Z.H.], Meyer Children's Hospital at Rambam Medical Center, 31096 Haifa, Israel
\end{abstract}

\begin{abstract}
Transition of growth from infancy to childhood is associated with activation of the GH-IGF-I axis. Children with a delayed infancy-childhood transition (DICT) are short as adults. Thus, age at ICT may impact on growth response to GH. The objective was to investigate associations between growth response to GH treatment and ICT timing in children with idiopathic short stature (ISS) in a randomized, controlled, multicenter trial, TRN 88-080. A total of 147 prepubertal children (mean age, $11.5 \pm 1.4 \mathrm{y}$ ) were randomized to receive $\mathrm{GH} 33 \mu \mathrm{g} / \mathrm{kg} / \mathrm{d}\left(\mathrm{GH}_{33}, n=43\right), \mathrm{GH} 67$ $\mu \mathrm{g} / \mathrm{kg} / \mathrm{d}\left(\mathrm{GH}_{67}, n=61\right)$, or no treatment $(n=43)$. Data on growth to final height $(\mathrm{FH})$ were analyzed after categorization into those with normal $(n=76)$ or delayed ICT $(n=71)$. Within the $\mathrm{GH}_{33}$ group, significant height gain at $\mathrm{FH}$ was only observed in children with a DICT $(p<0.001)$, with each month of delay corresponding to gain of $0.13 \mathrm{SD}$ score (SDS). For the $\mathrm{GH}_{67}$ group, the timing of the onset of the ICT had no impact on growth response. In conclusion, ISS children with a DICT responded to standard GH dose (better responsiveness), whereas those with a normal ICT required higher doses to attain a significant height gain to FH. (Pediatr Res 69: 504-510, 2011)
\end{abstract}

$\mathrm{T}_{\mathrm{s}}^{\mathrm{h}}$ he term idiopathic short stature (ISS) is used to describe stature in children who are short compared with their peers for unknown reasons. This definition is assigned after the exclusion of systemic diseases, hormone deficiencies, psychosocial deprivation, genetic diseases, and syndromes known to cause short stature (1). Among children classified as having ISS, there is great variability in factors such as height, BMI, IGF-I, IGF-binding protein 3 (IGFBP3) levels, degree of bone maturation, and timing of puberty. The considerable variability that is seen suggests that diverse underlying mechanisms are responsible for the observed growth impairment.

We have recently defined a second and larger subgroup of short individuals who have experienced a delay in the onset of the infancy-childhood transition (ICT) so-called DICT $(2,3)$.

Received October 22, 2010; accepted December 8, 2010.

Correspondence: Kerstin Albertsson-Wikland, M.D., Ph.D., Göteborg Pediatric Growth Research Center (GP-GRC), The Sahlgrenska Academy at University of Gothenburg, SE-416 85 Göteborg, Sweden; e-mail: kerstin.albertsson-wikland@pediat.gu.se

This study TR 88-080 was initiated in 1988 as a Kabi-sponsored study and changed to an Investigator-sponsored study in the 1990s. The study was supported by grants from Swedish Research Council (7509) and Foundation Växthuset for Children.

Z.H. guest professorship at University of Gothenburg was supported by Ipsen (20052007).

An unrestricted research grant and free drug was kindly provided by Pharmacia/Pfizer. B.J. and B.K. have received a consultancy fee from Pfizer. Pfizer had no influence on collection, analyses, and interpretation of data or in writing of this manuscript.
As many as $50 \%$ of cases of ISS can be explained by a delay in ICT, and such children show evidence of dysfunction within the GH-IGF-I hormone axis (2).

Recombinant human $\mathrm{GH}$ has been used to treat short stature in children with GH deficiency (GHD) since 1986 (4). This treatment has also been shown to increase growth and final height (FH) in children with ISS (5-8) and was approved for this indication by the US Food and Drug Administration in 2003. As expected for this heterogeneous population, longterm height gains vary, ranging from no gain to approximately +3 SD score (SDS) (8). Concerns about the ethical and economic ramifications of expanding the use of GH to children in whom the GH secretion is not deficient require that we have a better understanding of different mechanisms responsible for ISS and can define subgroups of patients according to their responsiveness to GH therapy. This has prompted us to explore the variables that are related to growth responsiveness to GH therapy in prediction models in children diagnosed with GHD or ISS (9-12): GH responsiveness was best estimated when incorporating information on growth during early life together with the $\mathrm{GH}$ maximum $\left(\mathrm{GH}_{\max }\right)$ spontaneous secretion (12) and useful for guiding GH dosing in a randomized clinical trial (13). Thus, the most important auxological factor for predicting growth in response to $\mathrm{GH}$ is the growth pattern during the first year of life-the greater the loss in relative height during infancy, the better will be the later growth response on $\mathrm{GH}$. We now suggest this growth pattern to be a sign of the onset of activation of the GH-IGF-I effect on growth, i.e. the time of the ICT (2).

It has previously been shown that the $\mathrm{GH}$ axis becomes active during the ICT (14) and that the surge in IGF-I and IGFBP3 levels that is known to occur during the first year of life coincides with the ICT (15). The ICT has also been found to be delayed in children with GHD $(2,14)$. These findings

\footnotetext{
Abbreviations: AGA, appropriate for GA; AITT, arginine-insulin tolerance test; DICT, delayed infancy-childhood transition; diffMPH $_{\text {SDS }}$, difference in child height $_{\mathrm{SDS}}$ versus midparental height $(\mathrm{MPH})_{\mathrm{SDS}} ; \mathbf{F H}$, final height; $\mathbf{G H}_{\mathbf{3 3}}$, GH dose $33 \mu \mathrm{g} / \mathrm{kg} / \mathrm{d} ; \mathbf{G H}_{\mathbf{6 7}}, \mathrm{GH}$ dose $67 \mu \mathrm{g} / \mathrm{kg} / \mathrm{d} ; \mathbf{G H D}$, growth hormone deficiency; $\mathbf{G H}_{\text {max }}$, maximum peak of GH; ICP, infancy-childhood-puberty; ICT, infancy-childhood-transition; ISS, idiopathic short stature; IGFBP3, insulin-like growth-factor-I-binding protein 3; ITT, intention-to-treat; MPH, midparental height; non-DICT, normal infancy-childhood-transition; PP, per-protocol; SDS, standard deviation score; SGA, small for GA
} 
have led to the current working hypothesis that age at onset of ICT may be an important variable/indicator for responsiveness to $\mathrm{GH}$ therapy. We would predict that children with a delay in the ICT will be more sensitive to $\mathrm{GH}$ treatment.

The present long-term, randomized, controlled, clinical trial was undertaken to evaluate the effects of $\mathrm{GH}$ treatment in short children who were non-GH deficient (8). Here, we reanalyze these data to evaluate the impact of $\mathrm{GH}$ treatment on $\mathrm{FH}$ in short non-GH-deficient children who were recategorized according to whether they had a normal or delayed ICT or not. This was not an inclusion or a randomization criterion of the original study, but it was possible to evaluate this parameter because growth of all the study children during infancy was followed prospectively in Swedish well-baby clinics.

\section{SUBJECTS AND METHODS}

The randomized, controlled study was conducted in accordance with declaration of Helsinki and Good Clinical Practice in 177 short non-GHdeficient children from six pediatric endocrinology units in Sweden who were enrolled in the study between 1988 and 1999. The protocol was approved by the Ethical Committees at Universities of Göteborg, Lund, Linköping, Uppsala, and Umeå and at Karolinska Institute in Sweden. Informed consent was obtained from all children and their parents.

Of the total population of 177 children, we were unable to determine the timing of ICT in four cases due to missing measurements. A further 26 children were excluded because of protocol violation (in 14 cases GH treatment was stopped prematurely; in 12 controls, GH or testosterone treatment was given). A total of 147 children comprised the intention-to-treat (ITT) population. Subjects were randomized into three groups. Children received GH treatment either at $33 \mu \mathrm{g} / \mathrm{kg} / \mathrm{d}\left(\mathrm{GH}_{33}, n=43\right)$ or $67 \mu \mathrm{g} / \mathrm{kg} / \mathrm{d}$ $\left(\mathrm{GH}_{67}, n=61\right)$, or remained untreated $(n=43)$, and ICT was found to be delayed in $49 \%, 53 \%$, and $42 \%$ of the children, respectively. Age at the start of the study for girls was $11.1 \pm 1.30$ (range, $8-13$ y) and for boys $11.7 \pm$ 1.39 (range, $10-15 \mathrm{y}$ ). No subject was GH deficient, and all subjects had a height during the prestudy period below -2 SDS according to Swedish growth standards (16). Furthermore, bone age according to TannerWhitehouse (TW2) was $\leq 11$ y in girls and $\leq 13$ y in boys. None of the children had a syndrome or any chronic disease. Of the children studied, 106 were prepubertal at the start of the study and adhered completely to the protocol, defined as the per-protocol (PP) population. During the pretreatment year, 31 children entered puberty, whereas 68 remained prepubertal during the first year of treatment. Forty children were born small for GA (SGA) $(17,18)$. In the past decade, short SGA children have been separated from the group of children with ISS (19). As the study was initiated long before this new classification, children with SGA were also included due to the randomization procedure.

Growth history. Height and weight measurements were made at neonatal, child, and school healthcare units from birth until prestudy start. An average of $9.0 \pm 3.6$ length/height measurements was obtained from each child before $3 \mathrm{y}$ of age. Supine length measurements were taken until $2 \mathrm{y}$ of age; thereafter, standing height was recorded. During the pretreatment year until FH, measurements were made using a Harpenden stadiometer at growth clinics of the university hospitals.

ICT. The data collected in the first $4 \mathrm{y}$ of life of the subject were fitted using a mathematical model that incorporated the functions and concepts of the first two components of Karlberg's infancy-childhood-puberty (ICP) growth model (20), as previously described $(2,14,20-22)$. The infancy component is modeled with a negative exponential function:

$$
Y=a_{\mathrm{I}}+b_{\mathrm{I}}\left[1-\exp \left(-c_{\mathrm{I}} t\right)\right]
$$

where the birth length is $a_{\mathrm{I}}$, the postnatal contribution of the infancy component is $b_{\mathrm{I}}$, and the growth rate of the infancy component is $c_{\mathrm{I}}$. The childhood component is represented by a second-degree polynomial function, where $t$ is age in years from birth:

$$
Y=a_{\mathrm{C}}+b_{\mathrm{C}} t+c_{\mathrm{C}} t^{2}
$$

Subjects were divided into two groups based on the timing of ICT: those for whom the start of ICT was within the normal range (ICT start 6-12 mo of age, non-DICT) and those for whom the start of ICT was delayed (ICT start $>12$ mo of age, DICT).
All measurements were plotted on the ICP growth model growth chart (20). The timing of ICT was determined to the nearest month by two observers, with a coefficient of variation $(\mathrm{CV})$ of less than 1 mo $(n=100)$, as previously described $(2,14,20-22)$.

Growth outcome variables. Three variables were used to evaluate treat-

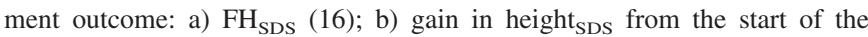
treatment versus the childhood component (20) to FH; and c) difference between $\mathrm{FH}_{\mathrm{SDS}}$ and midparental height ${ }_{\mathrm{SDS}}\left(\right.$ diffMPH $\left._{\mathrm{SDS}}\right)$. $\mathrm{MPH}_{\mathrm{SDS}}$ was calculated as (father's height $\mathrm{SDS}+$ mother's height $_{\mathrm{SDS}}$ )/1.61 (23). The height, weight, and BMI (24) of the children and the height of the parents were assessed relative to Swedish population-based growth references (16). The childhood component of the ICP model was used for all measurements before puberty (20); thereafter, the ordinary combined function of childhood and puberty was used (16).

FH was defined as the height achieved when annual growth was less than $1 \mathrm{~cm}$. The last height measured was used for calculations of the outcome variables versus the Swedish growth reference data for 18 y olds (16). Birth weight and length for GA and gender were calculated in $\operatorname{SDS}(17,18)$. Children were classified as being born SGA if birth length and/or weight was less than -2 SDS below the mean for GA $(17,18)$.

Hormonal evaluation. The hormonal analyses of GH $(25,26)$, IGF-I (27), IGFBP3 (28), and leptin (29) were performed at the GP-GRC laboratory (SWEDAC accreditation no. 1899). Arginine-insulin tolerance tests (AITT) were performed in all but two children and $\mathrm{GH}_{\max }$ identified. Twenty-fourhour GH profiles were obtained in all subjects, with 20-min integrated or discrete samples and $\mathrm{GH}_{\max }$ identified (25).

Statistical analyses. Statistical analyses were performed by a statistician (B.J.) using standard statistical package SPSS, version 15.0 (SPSS inc. Chicago, IL). Results are expressed as mean \pm SD unless otherwise indicated. Tests for statistical significance were performed using nonparametric tests of Wilcoxon type; Wilcoxon tests for within-group changes, Mann-Whitney $U$ tests for between-group differences, and Kruskal-Wallis tests for differences between more than two groups. $t$ tests were applied when data were normally distributed according to a Kolmogorov-Smirnov test $(p>0.20)$ : these cases will be denoted in text and tables. Simple linear regression analyses were used when correlating ICT to FH. Spearman rank correlation was applied in correlation analyses. Significance level was set at $p<0.05$. No corrections for multiplicity have been made as the study is explorative.

\section{RESULTS}

Pretreatment characteristics. Pretreatment characteristics of the ITT and PP populations were similar. However, when subdivided into those with a normal and a delayed ICT, there were differences in characteristics at birth (Table 1). Children with DICT were born later in terms of GA and were longer and heavier at birth than non-DICT children. The ICT occurred about 4 mo later $(p<0.001)$ in the DICT group, and this delay corresponded to a significantly reduced growth rate during the first 2 y of life $(p<0.001)$.

At the start of the study, children with DICT had lower IGF-I $_{\mathrm{SDS}}$ than non-DICT children (PP: $-0.97 \pm 1.19$ versus $-0.62 \pm 1.02$, respectively, $p<0.05$; ITT: $-0.99 \pm 1.13$ versus $-0.56 \pm 0.98$, respectively, $p<0.005)$. $\mathrm{GH}_{\max }$ at $24 \mathrm{~h}$ were similar in both groups (NS). Those with DICT were leaner (PP, $p<0.048$; ITT, $p<0.050 ; t$ test) and had a greater delay of bone age (PP, $p<0.029$; ITT, $p<0.008)$ than those with a normal ICT (Table 1). The short children born SGA did not differ in terms of pretreatment characteristics at the start of the study from ISS children born appropriate for GA (AGA).

First-year treatment response. First-year growth response was analyzed in the 68 children in the ITT population who remained prepubertal. For those receiving the $\mathrm{GH}_{33}$ dose, a growth response of $0.60 \pm 0.19$ SDS was found in the DICT group compared with $0.44 \pm 0.17$ SDS in the non-DICT group $(p=0.03)$. For the $\mathrm{GH}_{67}$ dose, the corresponding results were $0.74 \pm 0.19 \mathrm{SDS}$ and $0.77 \pm 0.24 \mathrm{SDS}(\mathrm{NS})$, respectively. A dose-response relationship with first-year 
Table 1. Pretreatment characteristics of the PP and ITT populations

\begin{tabular}{|c|c|c|c|c|c|c|c|c|c|}
\hline & \multirow[b]{2}{*}{ Group } & \multicolumn{4}{|c|}{$\mathrm{PP}(N=106)$} & \multicolumn{4}{|c|}{ ITT $(N=147)$} \\
\hline & & $\mathrm{N}$ & Mean & SD & $p<$ & $\mathrm{N}$ & Mean & SD & $p<$ \\
\hline \multicolumn{10}{|l|}{ At birth/early growth } \\
\hline \multirow{2}{*}{ ICT, mo } & Non-DICT & 52 & 10.2 & 1.76 & & 76 & 9.9 & 1.80 & \\
\hline & DICT & 54 & 14.0 & 1.08 & 0.001 & 71 & 14 & 1.29 & 0.001 \\
\hline \multirow[t]{2}{*}{$\Delta$ length birth to $2 \mathrm{y}$, SDS } & Non-DICT & 47 & -0.8 & 0.96 & & 67 & -0.7 & 1.02 & \\
\hline & DICT & 53 & -1.5 & 0.90 & 0.001 & 69 & -1.4 & 0.90 & 0.001 \\
\hline \multirow[t]{2}{*}{ GA, wk } & Non-DICT & 52 & 39.0 & 1.98 & & 76 & 39.0 & 1.96 & \\
\hline & DICT & 54 & 40.0 & 1.16 & 0.004 & 71 & 40.0 & 1.24 & 0.001 \\
\hline \multirow[t]{2}{*}{ Birth length SDS } & Non-DICT & 52 & -1.5 & 0.94 & & 76 & -1.7 & 1.08 & \\
\hline & DICT & 54 & -0.7 & 0.89 & 0.001 & 71 & -0.8 & 0.92 & 0.001 \\
\hline \multirow[t]{2}{*}{ Birth weight SDS } & Non-DICT & 52 & -1.0 & 0.96 & & 76 & -1.2 & 1.05 & \\
\hline & DICT & 54 & -0.4 & 0.87 & 0.001 & 71 & -0.5 & 0.92 & 0.001 \\
\hline \multirow[t]{2}{*}{ Midparental height SDS } & Non-DICT & 52 & -1.8 & 0.94 & & 76 & -1.8 & 0.87 & \\
\hline & DICT & 54 & -1.7 & 0.86 & NS & 71 & -1.7 & 0.83 & NS \\
\hline \multirow[t]{2}{*}{ Mother's height SDS } & Non-DICT & 52 & -1.6 & 1.04 & & 76 & -1.6 & 0.94 & \\
\hline & DICT & 54 & -1.3 & 0.95 & NS & 71 & -1.4 & 0.94 & 0.042 \\
\hline \multirow[t]{2}{*}{ Father's height SDS } & Non-DICT & 52 & -1.2 & 0.94 & & 76 & -1.2 & 0.95 & \\
\hline & DICT & 54 & -1.4 & 0.93 & NS & 71 & -1.3 & 0.92 & NS \\
\hline \multicolumn{10}{|l|}{ At study start } \\
\hline \multirow{2}{*}{ Pretreatment year $\Delta$ height SDS } & Non-DICT & 52 & 0.02 & 0.211 & & 76 & -0.11 & 0.380 & \\
\hline & DICT & 54 & -0.04 & 0.290 & NS & 71 & -0.07 & 0.319 & NS \\
\hline \multirow[t]{2}{*}{ Age, y } & Non-DICT & 52 & 11.14 & 1.248 & & 76 & 11.53 & 1.391 & \\
\hline & DICT & 54 & 11.46 & 1.458 & NS & 71 & 11.62 & 1.400 & NS \\
\hline \multirow[t]{2}{*}{ Height SDS } & Non-DICT & 52 & -2.64 & 0.398 & & 76 & -2.77 & 0.536 & \\
\hline & DICT & 53 & -2.75 & 0.577 & NS & 70 & -2.78 & 0.590 & NS \\
\hline \multirow[t]{2}{*}{ BMI SDS } & Non-DICT & 52 & -0.69 & 0.871 & & 76 & -0.69 & 0.947 & \\
\hline & DICT & 53 & -1.08 & 1.105 & $0.048^{*}$ & 70 & -1.02 & 1.061 & $0.050^{*}$ \\
\hline \multirow[t]{2}{*}{ DiffMPH $_{\text {SDS }}$} & Non-DICT & 52 & -1.27 & 0.912 & & 76 & -1.39 & 0.944 & \\
\hline & DICT & 54 & -1.47 & 0.971 & NS & 71 & -1.50 & 0.916 & NS \\
\hline \multirow[t]{2}{*}{$\mathrm{GH}_{\max } \mathrm{AITT} / 24 \mathrm{~h}, \mathrm{mU} / \mathrm{L}$} & Non-DICT & 51 & 47.87 & 23.506 & & 75 & 51.8 & 24.712 & \\
\hline & DICT & 51 & 47.2 & 25.165 & NS & 68 & 45.99 & 23.006 & NS \\
\hline \multirow[t]{2}{*}{ IGF-I SDS } & Non-DICT & 51 & -0.62 & 1.022 & & 74 & -0.56 & 0.981 & \\
\hline & DICT & 53 & -0.97 & 1.193 & 0.05 & 70 & -0.99 & 1.127 & 0.005 \\
\hline \multirow[t]{2}{*}{ IGFBP 3 SDS } & Non-DICT & 51 & -0.22 & 1.090 & & 75 & -0.12 & 1.066 & \\
\hline & DICT & 54 & -0.23 & 0.998 & NS & 71 & -0.23 & 1.070 & NS \\
\hline \multirow[t]{2}{*}{ Ratio IGF-I/IGFBP 3 SDS } & Non-DICT & 52 & -0.70 & 1.007 & & 76 & -0.64 & 1.002 & \\
\hline & DICT & 54 & -0.78 & 0.987 & NS & 71 & -0.80 & 0.956 & NS \\
\hline \multirow{2}{*}{ Bone age delay, y } & Non-DICT & 48 & -1.50 & 0.835 & & 69 & -1.38 & 0.915 & \\
\hline & DICT & 48 & -1.84 & 0.959 & 0.029 & 64 & -1.80 & 0.965 & 0.008 \\
\hline
\end{tabular}

Nonparametric Mann-Whitney $U$ test was used.

$* t$ test.

growth response was found in both the DICT group ( $p<$ $0.028)$ and the non-DICT group $(p<0.001)$.

First-year growth response for the 58 children in the PP population who remained prepubertal was also analyzed. For children on $\mathrm{GH}_{33}$, a growth response of $0.60 \pm 0.22$ SDS was found in the DICT group compared with $0.50 \pm 0.12$ SDS in the non-DICT group $\left(p=0.22\right.$; NS). For $\mathrm{GH}_{67}$, the corresponding results were $0.75 \pm 0.19$ SDS and $0.77 \pm 0.24$ SDS (NS; Fig. 1). A dose-response relationship with change in height $_{\text {SDS }}$ was found in the non-DICT group $(p<0.004)$ and also in the DICT group $(p<0.036)$.

For children in the control group who remained prepubertal during the first year of the study, there were no significant differences between growth during the first year of the study and during the pretreatment year for either the DICT or non-DICT groups: both subgroups continued to grow at a similar rate during the first year of the study to that during the pretreatment year (DICT: $-0.04 \pm 0.37$ SDS first year versus $0.09 \pm 0.16$ SDS pretreatment year; non-DICT: $-0.03 \pm 0.20$ first year versus $0.01 \pm 0.11$ SDS pretreatment year).

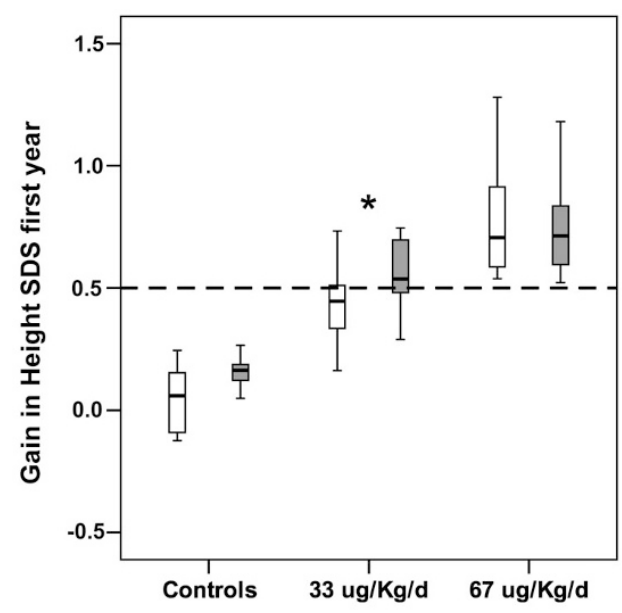

Figure 1. First-year growth response in controls and GH treated, 33 or 67 $\mu \mathrm{g} / \mathrm{kg} / \mathrm{d}$ in prepubertal ITT population with normal $(\square)$ or delayed ( $\square$ ICT. Box and whisker plots show median, interquartile range, and values within \pm 1.5 of the interquartile range. First-year growth response in the $\mathrm{GH}_{33}$ DICT group was significantly higher $\left({ }^{*} p<0.03\right)$ than in the $\mathrm{GH}_{33}$ non-DICT group. 
The first-year growth response of prepubertal $\mathrm{GH}_{33}$ DICT children correlated positively with the 3-mo ( $p<$ $0.043)$ and 12-mo IGF-I response $(p<0.011)$. No such correlation was found for the $\mathrm{GH}_{33}$ non-DICT individuals. When dividing the study population into children with ISS and those born SGA, results for both subgroups were similar to those for the total group.

FH outcomes. Comparing the effects of GH treatment on $\mathrm{FH}$ in the groups revealed that growth response in children receiving $\mathrm{GH}_{33}$ for whom timing of the ICT was normal was no better than the response of the control group. For the group with DICT receiving the same GH dose, FH (PP: $p<0.001$;

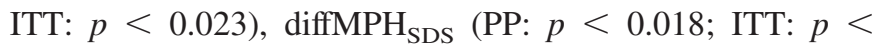
$0.026)$, and gain in height ${ }_{\mathrm{SDS}}$ from the start of the treatment (PP: $p<0.001$; ITT: $p<0.001$ ) were significantly greater than in controls. When comparing the DICT and non-DICT groups who received $\mathrm{GH}_{33}$, significantly greater outcome in the DICT group relative to the non-DICT group was found: FH (PP: $p<0.020$; ITT: $p<0.017$ ), diffMPH ${ }_{\mathrm{SDS}}$ (PP: $p<$

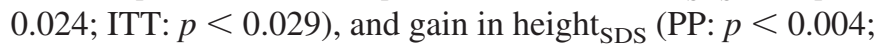
ITT: $p<0.002$ ). Among the children on $\mathrm{GH}_{67}$, both ICT groups responded with a similar increase in $\mathrm{FH}_{\mathrm{SDS}}$, diffMPH $\mathrm{SDS}_{\mathrm{S}}$,

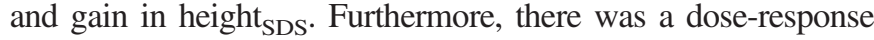
relationship for all three outcome variables for the non-DICT but not for the DICT group. In the untreated group, no significant difference in $\mathrm{FH}$ outcomes was detected between children with a normal or delayed ICT (Fig. 2; Table 2).

Using linear regression analyses separately for the $\mathrm{GH}_{33}$ and $\mathrm{GH}_{67}$ of the PP population, each month of delay in ICT for the $\mathrm{GH}_{33}$ group corresponded to a gain in $\mathrm{FH}_{\mathrm{SDS}}$ of 0.13 SDS $\left(p<0.03\right.$; Fig. 3). The slope was significant for the $\mathrm{GH}_{33}$ group but not for the $\mathrm{GH}_{67}$ group. Overall, when not separating the two doses, the slope was significant $(p<0.003)$ and the gain in FH of $0.12 \mathrm{SDS} / \mathrm{ICT}$ month.

Outcomes at FH in children with ISS. When children born SGA were excluded from the analysis, none of the outcome variables at $\mathrm{FH}$ differed between the DICT and non-DICT children on $\mathrm{GH}_{67}$. However, in $\mathrm{GH}_{33}$ all outcomes differed: DICT children were taller (PP: $p<0.019$; ITT: $p<0.003$ ), closer to $\mathrm{MPH}_{\mathrm{SDS}}$ (PP: $p<0.023$; ITT: $p<0.019$ ), and had gained more height (PP: $p<0.027$; ITT: $p<0.003$ ) than non-DICT children.

The $\mathrm{GH}_{33}$ DICT group showed a significant increase in FH

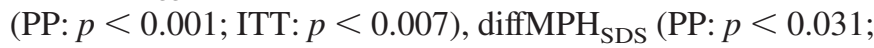
ITT: $p<0.067)$, and gain in height ${ }_{\mathrm{SDS}}$ from the start of the treatment (PP: $p<0.001$; ITT: $p<0.001$ ) relative to controls. The treatment response of the non-DICT individuals on $\mathrm{GH}_{33}$ did not differ significantly from those of the controls.

Also when explaining the variance in gain in height ${ }_{\mathrm{SDS}}$ with a multivariate analyses, no influence of SGA was found. The gain in height SDS $_{\text {was }}$ explained by high/low GH dose $(p<$ $0.001)$, familiar short stature $(p<0.002)$, and DICT ( $p=$ 0.015 ) but not by SGA $(p=0.503$, NS).

IGF-I response. The short-term response of IGF-I after GH treatment was similar in children with non-DICT and DICT (Fig. 4), despite the fact that children with DICT had lower baseline IGF-I levels (Table 1). Levels did not differ signifi-
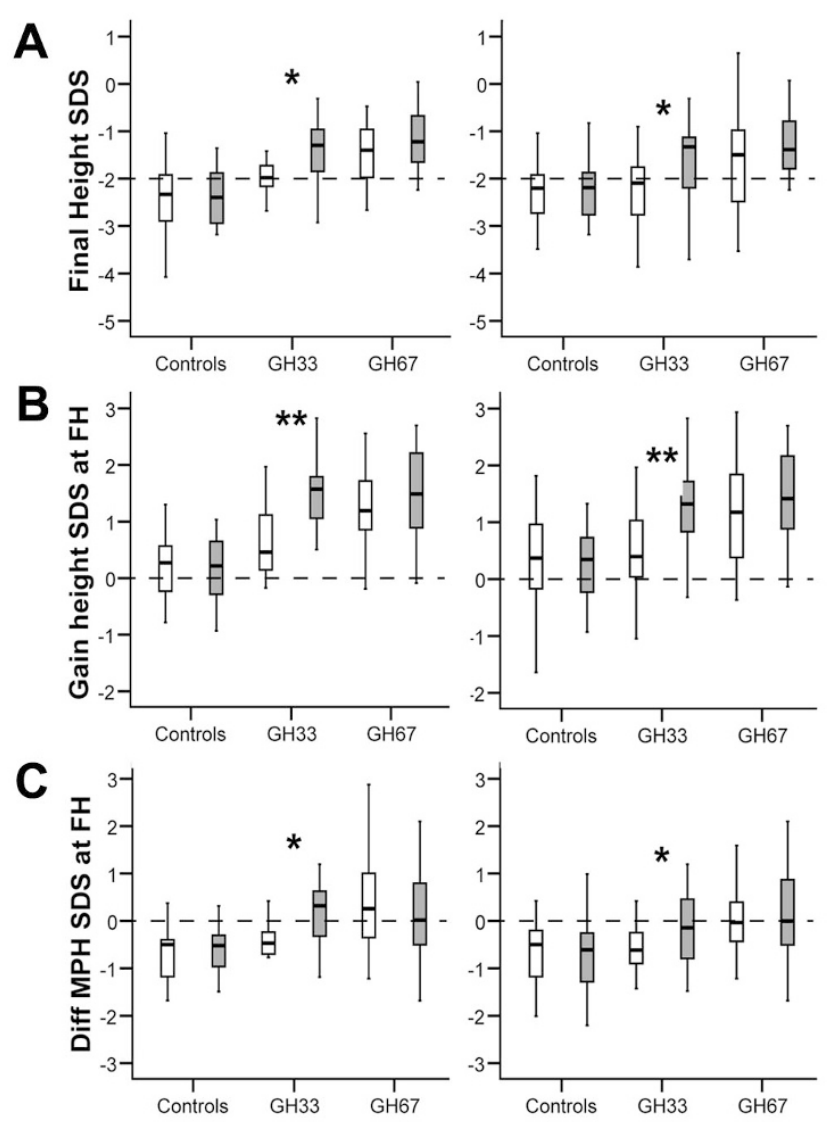

Figure 2. Final height $(\mathrm{FH})$ outcomes in PP. PP population (left) and ITT population (right) as $\mathrm{FH}_{\mathrm{SDS}}(A)$, gain in height $\mathrm{SDS}(B)$, and difference between $\mathrm{FH}_{\mathrm{SDS}}$ and midparental height ${ }_{\mathrm{SDS}}\left(\right.$ diffMPH $\left._{\mathrm{SDS}}\right)(C)$ in groups with normal (non-DICT, $\square$ ) or delayed (DICT, $\square$ ) ICT. Box and whisker plots show median, interquartile range, and values within \pm 1.5 of the interquartile range. $*$ and ** represent significant differences between DICT and non-DICT subjects in the $\mathrm{GH}_{33}$ group on $<0.03$ and $<0.005 p$ levels, respectively. Analyzing the dose response in DICT and non-DICT, dose response were significant $(p<0.03)$. Furthermore, comparing outcomes in the $\mathrm{GH}_{67}$ group with controls, all outcomes were significantly better in the $\mathrm{GH}_{67}$ group. When comparing outcomes between controls and $\mathrm{GH}_{33}$ group, only the DICT group responded better than controls ( $p$ levels $<0.05$ in all comparisons).

cantly at any time point. So, the IGF-I ${ }_{\text {SDS }}$ response did not differ between DICT and non-DICT children.

\section{DISCUSSION}

The controversy over the use of GH treatment in short non-GHD children has been based on ethical and cost-efficacy considerations. Characterizing subgroups of patients so far included in the ISS group that respond predictably to GH is of significant clinical interest. The identification of delayed age at ICT as a factor contributing to short stature in many children brings a new perspective into the discussion. As we previously reported, nearly half of individuals with ISS can be categorized as having DICT (2), and the number of individuals that this study applies to is quite substantial. Here, we show that DICT children respond to standard GH dose, whereas children with normal ICT need higher GH dose. Previously, it has been reported that a delay in ICT was associated with a dysfunctional GH-IGF-I axis $(2,3,15)$. We now report from a 
Table 2. Final growth outcome for all or only ISS children with normal (Non-DICT) and delayed ICT (DICT) in the per-protocol (PP) and the intention-to-treat (ITT) populations (panels)

\begin{tabular}{|c|c|c|c|c|c|c|c|c|c|c|}
\hline & \multicolumn{2}{|r|}{ Controls (C) } & \multicolumn{3}{|c|}{$\mathrm{GH}_{33}$} & \multicolumn{2}{|r|}{$\mathrm{GH}_{67}$} & \multicolumn{2}{|c|}{$p<$} & \multirow{2}{*}{$\begin{array}{l}\text { Dose reponse } \\
\mathrm{GH}_{33} \text { vs } \mathrm{GH}_{67}\end{array}$} \\
\hline & $n$ & Mean \pm SD & $n$ & Mean \pm SD & $\boldsymbol{p}(\mathrm{d})<$ & $n$ & Mean \pm SD & C vs $\mathrm{GH}_{33}$ & $\mathrm{C} v \boldsymbol{v} \mathrm{GH}_{67}$ & \\
\hline \multicolumn{11}{|l|}{ All PP } \\
\hline \multicolumn{11}{|l|}{ Non-DICT } \\
\hline Final height SDS & 17 & $-2.44 \pm 0.985$ & 15 & $-1.98 \pm 0.52$ & NS & 20 & $-1.46 \pm 0.899$ & NS & 0.003 & 0.028 \\
\hline Diff MPH, FH & 17 & $-0.70 \pm 0.568$ & 15 & $-0.65 \pm 1.038$ & NS & 20 & $0.33 \pm 1.164$ & NS & 0.001 & 0.008 \\
\hline Gain SDS at FH & 17 & $0.16 \pm 0.772$ & 15 & $0.64 \pm 0.637$ & NS & 20 & $1.21 \pm 0.721$ & NS & 0.001 & 0.028 \\
\hline \multicolumn{11}{|l|}{ DICT } \\
\hline Final height SDS & 12 & $-2.33 \pm 0.646$ & 17 & $-1.42 \pm 0.75$ & 0.020 & 25 & $-1.26 \pm 0.828$ & 0.001 & 0.001 & NS \\
\hline Diff MPH, FH & 12 & $-0.60 \pm 0.789$ & 17 & $0.15 \pm 0.713$ & 0.024 & 25 & $0.17 \pm 0.933$ & 0.018 & 0.014 & NS \\
\hline Gain SDS at FH & 12 & $0.16 \pm 0.586$ & 17 & $1.41 \pm 0.710$ & 0.004 & 25 & $1.57 \pm 0.771$ & 0.001 & 0.001 & NS \\
\hline \multicolumn{11}{|l|}{ All ITT } \\
\hline \multicolumn{11}{|l|}{ Non-DICT } \\
\hline Final height SDS & 25 & $-2.38 \pm 0.847$ & 22 & $-2.24 \pm 0.681$ & NS & 29 & $-1.65 \pm 0.916$ & NS & 0.005 & 0.011 \\
\hline Diff MPH, FH & 25 & $-0.65 \pm 0.780$ & 22 & $-0.74 \pm 0.922$ & NS & 29 & $0.10 \pm 1.087$ & NS & 0.003 & 0.002 \\
\hline Gain SDS at FH & 25 & $0.36 \pm 0.811$ & 22 & $0.50 \pm 0.704$ & NS & 29 & $1.18 \pm 0.857$ & NS & 0.001 & 0.009 \\
\hline \multicolumn{11}{|l|}{ DICT } \\
\hline Final height SDS & 18 & $-2.15 \pm 0.785$ & 21 & $-1.66 \pm 0.923$ & 0.017 & 32 & $-1.36 \pm 0.875$ & 0.023 & 0.001 & NS \\
\hline Diff MPH, FH & 18 & $-0.57 \pm 0.846$ & 21 & $-0.06 \pm 0.786$ & 0.029 & 32 & $0.15 \pm 0.997$ & 0.026 & 0.005 & NS \\
\hline Gain SDS at FH & 18 & $0.43 \pm 0.958$ & 21 & $1.24 \pm 0.743$ & 0.002 & 32 & $1.47 \pm 0.782$ & 0.001 & 0.001 & NS \\
\hline \multicolumn{11}{|l|}{ ISS PP } \\
\hline \multicolumn{11}{|l|}{ Non-DICT } \\
\hline Final height SDS & 10 & $-1.97 \pm 0.870$ & 8 & $-1.93 \pm 0.280$ & NS & 16 & $-1.37 \pm 0.944$ & NS & 0.077 & 0.023 \\
\hline Diff MPH, FH & 10 & $-0.57 \pm 0.550$ & 8 & $-0.58 \pm 0.418$ & NS & 16 & $0.25 \pm 1.266$ & NS & 0.027 & 0.013 \\
\hline Gain SDS at FH & 10 & $0.55 \pm 0.620$ & 8 & $0.66 \pm 0.736$ & NS & 16 & $1.24 \pm 0.737$ & NS & 0.031 & 0.016 \\
\hline \multicolumn{11}{|l|}{ DICT } \\
\hline Final height SDS & 10 & $-2.41 \pm 0.626$ & 16 & $-1.32 \pm 0.663$ & 0.019 & 22 & $-1.32 \pm 0.854$ & 0.000 & 0.001 & NS \\
\hline Diff MPH, FH & 10 & $-0.62 \pm 0.868$ & 16 & $0.09 \pm 0.69$ & 0.023 & 22 & $0.16 \pm 0.975$ & 0.031 & 0.039 & NS \\
\hline Gain SDS at FH & 10 & $0.10 \pm 0.565$ & 16 & $1.46 \pm 0.693$ & 0.027 & 22 & $1.50 \pm 0.783$ & 0.000 & 0.000 & NS \\
\hline \multicolumn{11}{|l|}{ ISS ITT } \\
\hline \multicolumn{11}{|l|}{ Non-DICT } \\
\hline Final height SDS & 15 & $-2.07 \pm 0.773$ & 12 & $-2.19 \pm 0.647$ & NS & 19 & $-1.43 \pm 0.900$ & NS & 0.021 & 0.004 \\
\hline Diff MPH, FH & 15 & $-0.65 \pm 0.624$ & 12 & $-0.61 \pm 0.421$ & NS & 19 & $0.19 \pm 1.165$ & NS & 0.006 & 0.003 \\
\hline Gain SDS at FH & 15 & $0.68 \pm 0.61$ & 12 & $0.48 \pm 0.774$ & NS & 19 & $1.15 \pm 0.750$ & NS & 0.060 & 0.032 \\
\hline \multicolumn{11}{|l|}{ DICT } \\
\hline Final height SDS & 15 & $-2.13 \pm 0.815$ & 18 & $-1.39 \pm 0.657$ & 0.003 & 28 & $-1.46 \pm 0.862$ & 0.007 & 0.007 & NS \\
\hline Diff MPH, FH & 15 & $-0.53 \pm 0.907$ & 18 & $0.00 \pm 0.699$ & 0.019 & 28 & $0.08 \pm 1.012$ & 0.067 & 0.067 & NS \\
\hline Gain SDS at FH & 15 & $0.49 \pm 0.993$ & 18 & $1.38 \pm 0.694$ & 0.003 & 28 & $1.37 \pm 0.783$ & 0.001 & 0.001 & NS \\
\hline
\end{tabular}

Children born SGA are included in the two upper panels and excluded from the two lower panels. $p(\mathrm{~d})$ denotes $p$ values when comparing DICT and Non-DICT individuals. All other comparisons are between groups. Nonparametric Mann-Whitney $U$ test was used.

randomized, controlled study that children treated with standard-dose GH $(33 \mu \mathrm{g} / \mathrm{kg} / \mathrm{d})$ with DICT respond better than non-DICT children. In addition, FH of non-DICT children receiving $\mathrm{GH}_{33}$ did not differ significantly from $\mathrm{FH}$ in the untreated control group. This raises the question of whether previous reports showing nonresponse to this dose of $\mathrm{GH}$ therapy in children with ISS may be related to a (nonobserved) selection bias toward non-DICT children.

Two methodological issues deserve consideration. Contemporary studies distinguish subjects with ISS born AGA from short children born SGA. As this study was initiated before the distinction was identified between ISS and short children born SGA (17), the present report included a subgroup of short children born SGA with incomplete catch-up growth. We have previously shown that the response to GH therapy is similar in short SGA children and ISS children when adjusted for their pretreatment auxology $(10,11)$, and hence we find it acceptable to report them as a joint group. In fact, the results of this study show similar results independent of being born AGA or SGA: DICT children being more GH responsive and also being the only group to gain height on $\mathrm{GH}_{33}$. Although this study was not designed with the current post hoc analysis in mind, the sample turned out to be well balanced, with 52 non-DICT and 54 DICT children in the PP population and 76 non-DICT and 71 DICT children in the ITT population. The same was true for the three treatment groups (Table 2). Despite these limitations, the results prove the concept of ICT-dependent growth in response to GH therapy.

Conventional teaching of growth patterns holds that crossing percentile curves during the first 2-3 y of life is acceptable (finding one's growth channel). In previous reports, our prediction models included early growth $(0-2 \mathrm{y})$ as a parameter for predicting the growth response to GH treatment $(9-12)$, and we found that early growth patterns (i.e. loosing length or keeping relative length) are as a strong predictor of $\mathrm{FH}$ as IGF-I levels or $\mathrm{GH}_{\max }$ during provocation tests (9). Modeling such growth patterns by the ICP method suggests that "finding one's channel" happens around the ICT. Our analyses show for the first time that children with DICT had a better longterm height gain and FH after a standard low GH dose than 


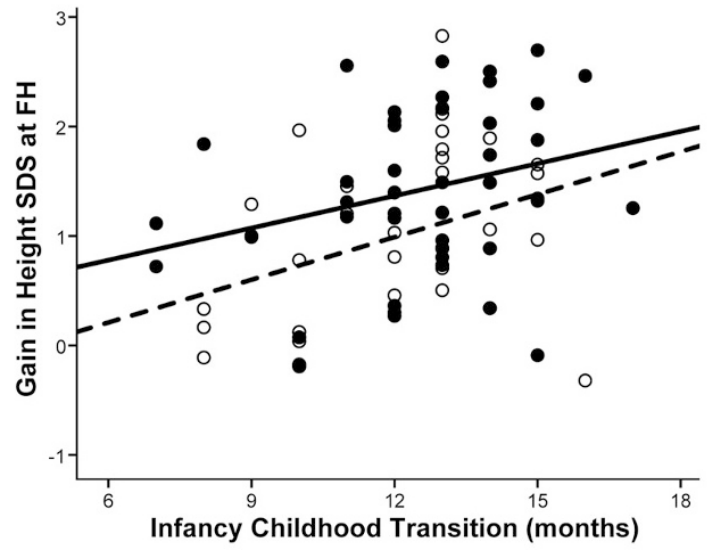

Figure 3. Age (mo) at the ICT in relation to gain in height ${ }_{S D S}$ from study start to final height $(\mathrm{FH})$ for the GH-treated children of the PP population according to GH dose: $(\bullet)=67 \mu \mathrm{g} / \mathrm{kg} / \mathrm{d}$ (solid line) and $(\circ)=33 \mu \mathrm{g} / \mathrm{kg} / \mathrm{d}$ (dotted line). The slope was significant for $\mathrm{GH}_{33}$ but not for $\mathrm{GH}_{67}$. The $\mathrm{GH}_{33}$ height gain per ICT month was 0.13 SDS (95\% CI: 0.02-0.25; $p<0.03$ ). Overall, when combining the gain in height $\mathrm{SDS}$ results from $\mathrm{GH}_{33}$ and $\mathrm{GH}_{67}$, the slope was significant, $0.12 \mathrm{SDS} / \mathrm{mo}$ (95\% CI: $0.04-0.20 ; p<0.003$ ). Similar results were obtained in the ITT population, where the gain per month in $\mathrm{GH}_{33}$ was 0.14 (95\% CI: $\left.0.04-0.25 ; p<0.010\right)$.
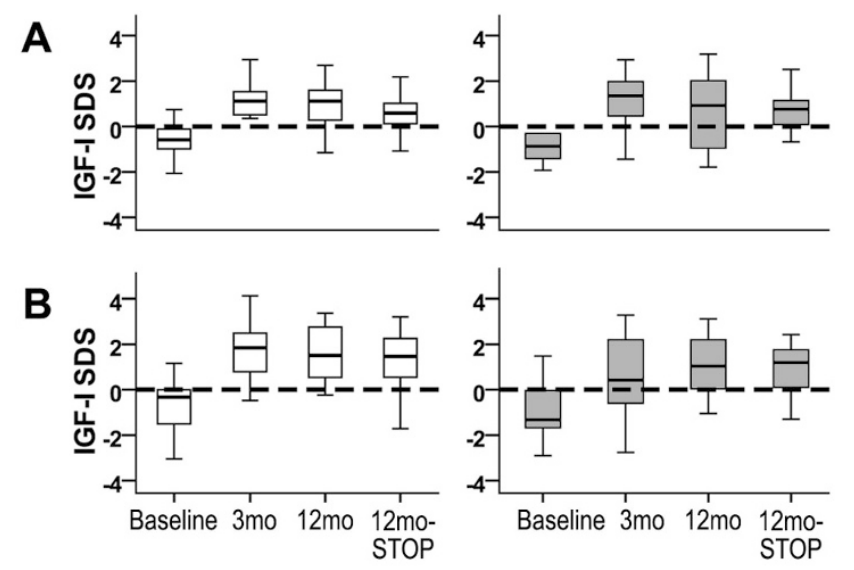

Figure 4. IGF- $\mathrm{I}_{\mathrm{SDS}}$ at baseline, at 3 and $12 \mathrm{mo}$, and the mean from $12 \mathrm{mo}$ until GH stop in the PP population with normal (left, non-DICT $\square$ ) or delayed (right, DICT $\square$ ) ICT according to GH dose $33 \mu \mathrm{g} / \mathrm{kg} / \mathrm{d}(A)$ or $67 \mu \mathrm{g} / \mathrm{kg} / \mathrm{d}(B)$. Box and whisker plots show median, interquartile range, and values within \pm 1.5 of the interquartile range. No significant differences between DICT and non-DICT treated subjects were observed. Furthermore, the IGF-I levels did not differ significantly between the dose groups.

children with a normal ICT. Children with DICT gained an average of $1.4 \mathrm{SD}(9 \mathrm{~cm})$ in $\mathrm{FH}$ when receiving the lower $\mathrm{GH}$ dose, whereas non-DICT children gained $0.64 \mathrm{SD}(4 \mathrm{~cm})$. The latter was not significantly different from the gain in untreated controls. With each month of ICT delay, the GH-induced height gain to FH increased by 0.13 SDS. Thus, we propose that retarded growth velocity during the first $0-2 \mathrm{y}$ of life can be a significant signal of disturbed GH/IGF-I axis activity, challenging conventional teaching about crossing channels during this period of life being acceptable.

Retarded growth in early life should not be confused with constitutional delay of growth and puberty, with a normal growth rate during early life and childhood that slows down around juvenility, and lack signs of puberty at an age of $2 \mathrm{SD}$ above the mean chronological age for puberty onset (3). In this study, analysis of the timing of puberty showed comparable ages both at onset of puberty and when FH was reached for DICT and non-DICT children. This allowed us to reject the constitutional delay of growth and puberty (CDGP) hypothesis as a reason for the height gain in our study group.

In conclusion, in this controlled clinical trial in which the children were randomized to a low-standard $(33 \mu \mathrm{g} / \mathrm{kg} / \mathrm{d})$ or high $(67 \mu \mathrm{g} / \mathrm{kg} / \mathrm{d}) \mathrm{GH}$ dose, children with DICT had both a greater short-term and long-term growth response to standarddose GH treatment than children with a normal ICT. The latter group of children required a higher $\mathrm{GH}$ dose to achieve similar gain in height. As such, there is a rationale for using standarddose GH therapy for children with DICT and high-dose therapy for children with a normal timing of ICT.

Acknowledgments. We thank the study group for allowing us to use the data for this analysis. The study group included Kerstin Albertsson-Wikland, A. Stefan Aronson, Jan Gustafsson, Lars Hagenäs, Sten A. Ivarsson, Berit Kriström, Claude Marcus, Karl Olof Nilsson, E. Martin Ritzén, Torsten Tuvemo, Otto Westphal, and Jan Åman.

\section{REFERENCES}

1. Wit JM, Clayton PE, Rogol AD, Savage MO, Saenger PH, Cohen P 2008 Idiopathic short stature: definition, epidemiology, and diagnostic evaluation. Growth Horm IGF Res 18:89-110

2. Hochberg Z, Albertsson-Wikland K 2008 Evo-devo of infantile and childhood growth. Pediatr Res 64:2-7

3. Hochberg Z 2009 Evo-devo of child growth II: human life history and transition between its phases. Eur J Endocrinol 160:135-141

4. Albertsson-Wikland K 1987 Clinical trial with authentic recombinant somatropin in Sweden and Finland. Acta Paediatr Scand Suppl 331:28-34

5. Hintz RL, Attie KM, Baptista J, Roche A 1999 Effect of growth hormone treatment on adult height of children with idiopathic short stature. Genentech Collaborative Group. N Engl J Med 340:502-507

6. Leschek EW, Rose SR, Yanovski JA, Troendle JF, Quigley CA, Chipman JJ, Crowe BJ, Ross JL, Cassorla FG, Blum WF, Cutler GB Jr, Baron J 2004 Effect of growth hormone treatment on adult height in peripubertal children with idiopathic short stature: a randomized, double-blind, placebo-controlled trial. J Clin Endocrinol Metab 89:3140-3148

7. Wit JM, Rekers-Mombarg LT, Cutler GB, Crowe B, Beck TJ, Roberts K, Gill A, Chaussain JL, Frisch H, Yturriaga R, Attanasio AF 2005 Growth hormone (GH) treatment to final height in children with idiopathic short stature: evidence for a dose effect. J Pediatr 146:45-53

8. Albertsson-Wikland K, Aronson AS, Gustafsson J, Hagenäs L, Ivarsson SA, Jonsson B, Kriström B, Marcus C, Nilsson KO, Ritzen EM, Tuvemo T, Westphal O, Åman J 2008 Dose-dependent effect of growth hormone on final height in children with short stature without growth hormone deficiency. J Clin Endocrinol Metab 93:4342-4350

9. Albertsson-Wikland K, Kristrom B, Rosberg S, Svensson B, Nierop AF 2000 Validated multivariate models predicting the growth response to $\mathrm{GH}$ treatment in individual short children with a broad range in GH secretion capacities. Pediatr Res 48:475-484

10. Dahlgren J, Kriström B, Niklasson A, Nierop AF, Rosberg S, Albertsson-Wikland K 2007 Models predicting the growth response to growth hormone treatment in short children independent of GH status, birth size and gestational age. BMC Med Inform Decis Mak 7:40

11. Kriström B, Dahlgren J, Niklasson A, Nierop AF, Albertsson-Wikland K 2009 The first-year growth response to growth hormone treatment predicts the long-term prepubertal growth response in children. BMC Med Inform Decis Mak 9:1

12. Kriström B, Löfqvist C, Rosberg S, Albertsson-Wikland K 2001 Effect of spontaneous GH secretion and the GH sampling period on the accuracy of models for predicting growth responses to GH treatment. J Clin Endocrinol Metab 86:49634964

13. Kriström B, Aronson AS, Dahlgren J, Gustafsson J, Halldin M, Ivarsson SA, Nilsson NO, Svensson J, Tuvemo T, Albertsson-Wikland K 2009 Growth Hormone (GH) dosing during catch-up growth guided by individual responsiveness decreases growth response variability in prepubertal children with gh deficiency or idiopathic short stature. J Clin Endocrinol Metab 94:483-490

14. Karlberg J, Albertsson-Wikland K 1988 Infancy growth pattern related to growth hormone deficiency. Acta Paediatr Scand 77:385-391

15. Leger J, Noel M, Limal JM, Czernichow P 1996 Growth factors and intrauterine growth retardation. II. Serum growth hormone, insulin-like growth factor (IGF) I, and IGF-binding protein 3 levels in children with intrauterine growth retardation 
compared with normal control subjects: prospective study from birth to two years of age. Study Group of IUGR. Pediatr Res 40:101-107

16. Albertsson-Wikland K, Luo ZC, Niklasson A, Karlberg J 2002 Swedish populationbased longitudinal reference values from birth to 18 years of age for height, weight and head circumference. Acta Paediatr 91:739-754

17. Karlberg J, Albertsson-Wikland K 1995 Growth in full-term small-for-gestationalage infants: from birth to final height. Pediatr Res 38:733-739

18. Niklasson A, Ericson A, Fryer JG, Karlberg J, Lawrence C, Karlberg P 1991 An update of the Swedish reference standards for weight, length and head circumference at birth for given gestational age (1977-1981). Acta Paediatr Scand 80:756-762

19. Clayton PE, Cianfarani S, Czernichow P, Johannsson G, Rapaport R, Rogol A 2007 Management of the child born small for gestational age through to adulthood: a consensus statement of the International Societies of Pediatric Endocrinology and the Growth Hormone Research Society. J Clin Endocrinol Metab 92:804-810

20. Karlberg J 1989 On the construction of the infancy-childhood-puberty growth standard. Acta Paediatr Scand Suppl 356:26-37

21. Liu YX, Albertsson-Wikland K, Karlberg J 2000 New reference for the age at childhood onset of growth and secular trend in the timing of puberty in Swedish. Acta Paediatr 89:637-643

22. Xu X, Wang W, Guo Z, Karlberg J 2002 Longitudinal growth during infancy and childhood in children from Shanghai: predictors and consequences of the age at onset of the childhood phase of growth. Pediatr Res 51:377-385
23. Luo ZC, Albertsson-Wikland K, Karlberg J 1998 Target height as predicted by parental heights in a population-based study. Pediatr Res 44:563-571

24. Karlberg J, Luo ZC, Albertsson-Wikland K 2001 Body mass index reference values (mean and SD) for Swedish children. Acta Paediatr 90:1427-1434

25. Albertsson-Wikland K, Rosberg S 1988 Analyses of 24-hour growth hormone profiles in children: relation to growth. J Clin Endocrinol Metab 67:493-500

26. Jansson C, Boguszewski C, Rosberg S, Carlsson L, Albertsson-Wikland K 1997 Growth hormone $(\mathrm{GH})$ assays: influence of standard preparations, $\mathrm{GH}$ isoforms, assay characteristics, and GH-binding protein. Clin Chem 43:950-956

27. Löfqvist C, Andersson E, Gelander L, Rosberg S, Blum WF, Albertsson-Wikland K 2001 Reference values for IGF-I throughout childhood and adolescence: a model that accounts simultaneously for the effect of gender, age, and puberty. J Clin Endocrinol Metab 86:5870-5876

28. Löfqvist C, Andersson E, Gelander L, Rosberg S, Hulthen L, Blum WF, AlbertssonWikland K 2005 Reference values for IGF-I Binding Protein-3 (IGFBP-3) and the ratio of IGF-I to IGFBP-3 throughout childhood and adolescence. J Clin Endocrinol Metab 90:1420-1427

29. Carlsson B, Ankarberg C, Rosberg S, Norjavaara E, Albertsson-Wikland K, Carlsson LM 1997 Serum leptin concentrations in relation to pubertal development. Arch Dis Child 77:396-400 